\title{
La experiencia de ocio en la naturaleza como fundamento de la construcción de sentido del lugar: el caso del Parque Natural de Urkiola, Bizkaia, Euskadi, España ${ }^{1}$
}

\author{
Andrés Ried Luci²
}

\begin{abstract}
RESUMEN
Este artículo identifica y caracteriza los vínculos que establecen aficionados de ocio en la naturaleza con algunos territorios protegidos. El texto hace referencia a la discusión teórica sobre el concepto de experiencia de ocio y cómo este, se constituye en factor determinante de la relación de los sujetos con el territorio estudiado. A través del análisis cualitativo de entrevistas en profundidad, se identificaron y categorizaron los significados que aficionados al ocio en la naturaleza asignaban a un territorio natural particular: sentidos de pertenencia e identidad, valoraciones del parque como lugar de socialización privilegiado, reservorio de magia, mitología y tradiciones culturales, emergieron como relevantes. Se afirma que las experiencias de ocio orientadas al contacto con la naturaleza, proveen de vivencias que transforman el espacio en un lugar, estableciendo lazos que tienden a generar conductas de admiración, cuidado y compromiso ambiental en los aficionados a la naturaleza.
\end{abstract}

Palabras clave: Experiencia de ocio, contacto con la naturaleza, identidad, sentido del lugar, lugares.

\begin{abstract}
This article identifies and characterizes the links established between outdoor recreationists and protected areas. The text refers to the theoretical discussion of leisure experiences and constitutes a determinant of the relationship between subjects and parks. Through qualitative analysis of interviews, we identified and categorized the significance that outdoor enthusiasts place on a specific natural are: a sense of belonging and identity; the park as a place of privileged socialization; reservoirs of magic, cultural traditions and mythology. Leisure experiences based on contact with nature, provide experiences that transform the space into a place, building ties that tend to generate behaviors of admiration, commitment and care for the environment and nature.
\end{abstract}

Key words: Outdoor experiences, connection with nature, identity, sense of place, places.

\footnotetext{
Artículo recibido el 6 enero de 2014, aceptado el 16 de septiembre de 2014 y corregido el 24 de noviembre de 2014.
}

\footnotetext{
2 Pontificia Universidad Católica de Chile (Chile). Email: rried@uc.cl
} 
En las últimas cinco décadas, el ocio, sus características y alcances, se ha constituido en un fenómeno de interés para diversos investigadores y publicaciones ${ }^{3}$, y entre las conclusiones más relevantes se ha demostrado que ocio es mucho más que esparcimiento y frivolidad. De hecho, ha sido tal la importancia que ha adquirido, que ya a mediados del siglo pasado, en el marco de la declaración universal de los derechos humanos se le reconocía su categoría de derecho humano fundamental, el texto del artículo 24 indica "Toda persona tiene derecho al descanso, al disfrute del tiempo libre, a un limitación razonable de la duración de su trabajo y a vacaciones periódicas pagadas" (Naciones Unidas, 1948). Esto sitúa al ocio, sin duda, como un fenómeno de alcances humanistas a nivel global $y$, si bien es cierto existe una dificultad para consensuar una definición de él, hay un acuerdo bastante asentado respecto de algunas características cardinales del mismo. Ya se ha superado la noción inicial del ocio como una actividad solo recreativa, por lo que tampoco es probable encontrar defensores del ocio como un tiempo específico o un tipo de actividad. Hoy en día, la idea de que el ocio es una experiencia subjetiva, libremente elegida y satisfactoria, un fenómeno personal pero de alcances sociales es una cuestión propuesta y aceptada por los más destacados estudiosos e investigadores del tema (Neulinger, 1974; Kaplan \& Kaplan, 1989; Iso-Ahola, 1980; Csikszentmihalyi \& Kleiber, 1991; World Leisure and Recreation, 1994; Dattilo et al., 1994; Cuenca, 2003, 2006; Csikszentmihalyi, 1997; Manell \& Kleiber, 1997; Pigram \& Jenkins, 1999; Manning, 1999; Driver et al., 1999; Henderson et al., 2001). No obstante existen aproximaciones que asocian al ocio como una industria y la sitúan como un sector de la economía, para este artículo se optará por caracterizar brevemente la perspectiva desde la cual esta investigación partió como concepto fundamental.

3 Como referencia se puede citar los trabajos de Neulinger (1974), Iso-Ahola (1980), Cszikzentmlihalyi (1987), Manell \& Kleiber (1997), Cuenca (2003, 2006), entre otros, y la existencia de revistas científicas que recogen investigaciones y estudios que dan cuenta del desarrollo del campo de estudios del ocio. Algunas de las más relevantes son Leisure Science, Journal of Leisure Research, Journal of Recreation, Parks and Management y ADOZ.
Esta es el ocio humanista y se entiende como "una experiencia humana integral, es decir, total, compleja (direccional y multidimensional), centrada en actuaciones queridas (libres, satisfactorias), autotélicas (con un fin en sí mismas) y personales (con implicaciones individuales y sociales). También como un derecho humano básico que favorece el desarrollo humano" (Cuenca, 2006: 14). Así, se afirma, que el ocio se puede considerar como una experiencia que favorece el desarrollo humano, ya que a través de su vivencia, pretende que los seres humanos puedan encaminarse a la felicidad, satisfacer múltiples necesidades, alcanzar grados crecientes de autonomía y promover una articulación orgánica entre seres humanos y naturaleza (Max Neef et al., 1986).

El ocio y sus múltiples manifestaciones (deporte, cultura, recreación y turismo) es capaz de proveer experiencias gratificantes y positivas en sí mismas, además de ofrecer la oportunidad de satisfacer carencias y/o desarrollo de potenciales que contribuyen al progreso integral de las personas y las sociedades. Estos efectos o resultados positivos y gratificantes de la práctica de ocio, se definen en la literatura como "beneficios de ocio"4. Estos beneficios, junto con satisfacer diversas necesidades inherentes al ocio, actúan como elemento catalizador de la satisfacción de otras necesidades humanas directa e indirectamente (Max Neef et al., 1986). Como, por ejemplo, tómese una práctica habitual de salir a la montaña con amigos, esto no solo permite satisfacer necesidades de escape, búsqueda y competencia (Iso-Ahola, 1980), sino que a su vez favorece la satisfacción de necesidades relacionadas con la interacción social, el desarrollo físico, el mantenimiento de la salud, la conexión con la naturaleza, la

\footnotetext{
4 Según Driver et al., (1999), los beneficios de ocio "se pueden entender mejor si se consideran la existencia de tres formas de concebirlos: como un cambio de las condiciones actuales de las personas o grupos de personas, a una condición deseada; el logro de una condición determinada o la prevención del deterioro de esa condición y la realización de experiencias recreativas psicológicas satisfactorias, tales como; relajación mental, tranquilidad, disfrute de la naturaleza, desarrollo de habilidades, aprendizaje, unidad familiar, etc.".
} 
identidad, aprendizaje, de bienestar espiritual y otros (Driver et al., 1991).

Los alcances de diversas manifestaciones del ocio, como por ejemplo el turismo, han sido destacadas como uno de los más importantes factores potenciales para el mejoramiento y conservación de la biodiversidad, a través del disfrute y la educación.

“...Si bien el turismo por sí solo no es suficiente para prestar apoyo a las áreas protegidas o el desarrollo comunitario, puede aportar beneficios económicos, oportunidades para las comunidades, oportunidades para la adquisición de tierras destinadas al establecimiento de áreas protegidas, una mayor valoración del patrimonio natural y cultural, un mayor conocimiento de la interacción entre los seres humanos y su medio ambiente, y un mayor interés y compromiso en la conservación de los valores naturales y culturales..." (UICN, 2003).

Lo antecedentes presentados permiten acentuar la importancia del ocio como referente del desarrollo humano y, por lo tanto, su relevancia como campo de estudio y fenómeno social que beneficia a las personas. A continuación se plantea como específicamente la experiencia de ocio en la naturaleza influye de manera gravitante en la concepción del territorio donde se despliega la vivencia.

\section{La experiencia de ocio en la naturaleza como determinante de los sentidos del lugar}

La influencia del ambiente en la experiencia de ocio es un factor determinante de la vivencia, se afirma que aunque resulte obvio que toda experiencia de ocio sucede en algún ambiente, no es menos cierto que la interacción a través de la cual el lugar define (aunque no completamente) la vivencia personal, es más rica y compleja de lo que se reconoce habitualmente (Iso-Ahola, 1980). Se asevera que existen un conjunto de manifestaciones del ocio en las cuales el lugar se convierte en el fin de la experiencia de ocio, más aún, es el objeto de disfrute y de interés, que se constituye en algo inseparable de la conducta de ocio (Iso-Ahola, 1980; Cuenca,
2010). La teoría del Ocio Humanista desarrollada por el Instituto de Estudios de Ocio, de la Universidad de Deusto categoriza estas manifestaciones de ocio, en la denominada Dimensión Ambiental-Ecológica ${ }^{5}$. Sintéticamente esta dimensión se puede definir como ciertas experiencias de ocio que se viven gracias al medio físico o espacio en el que se manifiestan. Es decir, el espacio no solo es elemento necesario sino que se convierte en detonante de la experiencia. Este artículo se refiere más precisamente al ocio que se desarrolla en la naturaleza y que considera a esta como condición sine qua non para su existencia. En estos términos, se puede entender ocio en la naturaleza como las experiencias subjetivas, libres y libertarias, que no tienen más fin que sí mismas, que se desarrollan en estrecho contacto y encuentro con y por la naturaleza, de gran alcance e impacto social y económico, que se viven como vivencias significativas y que reportan una serie de beneficios de orden físico, psicológico, social, económico y ambiental (Ried, 2012).

El ocio en la naturaleza, se asocia normalmente con diferentes manifestaciones del ocio, tales como; el deporte, la recreación y el turismo, y son de una diversidad y dinamismo sorprendente, desde los deportes de aventura, pasando por el ecoturismo, hasta los encuentros y retiros espirituales, consideran a la naturaleza como una condición para su desarrollo. El incremento en las prácticas de ocio, la diversificación, masificación y especialización de las mismas, lo posicionan como una manifestación con un presente y futuro destacado en el fenómeno del ocio contemporáneo. Esto lejos de retroceder parece ir en progresivo incremento, diversos autores destacan la diversidad e importancia de este tipo de manifestaciones (Ibrahim \& Cordes, 1993; Pigram \& Jenkins, 1999; Tarrant et al., 1999; Manning, 1999 2000; Cordell \& Super, 2000) y han registrado y vaticinado un sostenido crecimiento de las mismas (Heintzman, 2010). El crecimiento en el número de practicantes y aficionados, su dinamismo, su incremento en tecnología y perfeccionamiento en habilidades, sugieren que

\footnotetext{
5 Manuel Cuenca (2003) categoriza el ocio en cinco dimensiones: la dimensión lúdica; la dimensión creativa; la dimensión festiva, la dimensión ambiental-ecológica y la dimensión solidaria.
} 
es un ámbito de la experiencia humana bajo el cual se encuentran razones y vivencias complejas que podrían explicarse no solo desde la óptica de la cantidad, del placer, el consumo y el uso del tiempo libre, sino que contendría valores, perspectivas y potencialidades de alto interés para la sociedad y el ambiente ¿cuáles de estos se relacionan directamente con las áreas silvestres protegidas?, ¿cómo influyen en la asignacion de sentidos a los territorios naturales?

\section{Vínculos con el territorio o Sense of Place}

La experiencia de ocio en la naturaleza, tiene unos potenciales ligados a la satisfacción intrínseca que produce su vivencia, a los beneficios que promueve su práctica en las personas, a los alcances como herramienta para el desarrollo personal y del despertar de conciencia ambiental de sus aficionados. Las vivencias de ocio en contacto con la naturaleza contienen otro elemento relevante de destacar y advertir que dice relación con el hecho de que a partir de las experiencias de ocio en la naturaleza, las personas pueden percibir y generar vínculos más profundos, ocultos y permanentes con los espacios naturales, transformando estos espacios en lugares especiales (Williams et al., 1992). Estos vínculos han sido denominados, en la literatura científica genéricamente como sense of place (Tuan, 1977).

La noción de sense of place ha sido considerada como un concepto elusivo, complejo y difícil de definir, con una gran diversidad de valores asociados a el (Williams \& Stewart, 1998; Eisenhauer et al., 2000; Brooks et al., 2004; Davenport \& Anderson, 2005). Al surgir su definición como una noción fenomenológica, se destaca su carácter subjetivo, en muchos casos emergentes y con una clara orientación holística. Llama la atención que estas características sean similares a lo descrito respecto de la experiencia de ocio en la naturaleza. De hecho, para alguno autores sense of place, es un paso lógico que sigue a la perspectiva de los beneficios del ocio e, incluso, para algunos autores ha sido reconocido como un beneficio de orden superior o final (Driver et al., 1991; Driver et al., 1994; Manning, 1999; Roggenbuck \& Driver, 2000). Para otros investigadores, su dinamismo, apertura y su constante retroalimentación en relación con los significados que se le atribuyen, lo hace similar al concepto de ecosistema, en tanto sistema abierto y evolutivo (Williams \& Stewart, 1998). A estas comparaciones, se suma la convicción de que sense of place tiene alcances sociales de trascendencia, ya que se entiende que la manera en la cual los lugares son dotados de identidad no solo es una cuestión de experiencia personal y subjetiva, sino también como una cualidad que permite atribuir identidad colectiva a los territorios. Esto último es de gran interés si se considera que este sentimiento o sentido del lugar puede expresarse a nivel local, regional e incluso nacional, pues ciertamente existen posturas que plantean que puede existir un sentido de sense of place planetario $\mathrm{o}$, en otras palabras, el desarrollo de un yo ecológico, donde la personas se identifican como pertenecientes e integrados vital y totalmente al universo (Naess, 1988).

A partir de su enunciación, han ido surgiendo especificaciones sobre el modo de analizar y estudiar el sense of place, tales como el enfoque de place attachment (Williams et al., 1992) y el place meaning y special places (Schroeder, 2000). En todo caso, estas definiciones "se refieren a las conexiones que las personas tienen y desarrollan con la Tierra, sus percepciones de la relación entre ellos mismos y el lugar, tratándose de un concepto que engloba aspectos simbólicos y emocionales" (Eisenhauer et al., 2000: 422). Es decir, se refiere al vínculo que se genera entre una persona y un lugar específico. Otros autores, sugieren que el vínculo afectivo que se establece entre las personas y la naturaleza, producto de la relación recreativa, es un concepto central y determinante a la hora de entender las emociones, creencias y compromisos que se desarrollan en el marco de la experiencia de ocio en la naturaleza (Quinlan-Cutler \& Carmichael, 2010).

\section{La transformación del espacio al lugar: el rol de la experiencia de ocio}

Un punto que se ha entendido como un elemento fundacional de la noción de sense of place, ha sido el proceso mediante el cual un espacio físico se transforma en lugar, vale decir, cuando a propósito de la experiencia personal y colectiva, el espacio adquiere sentido y significado, generando procesos de 
identidad e identificación. El espacio se ve como un lugar indiferenciado hasta que, producto de la experiencia, el conocimiento y el tiempo se convierten en lugar (Relph, 1976; Tuan, 1977). Esta afirmación es representativa de una perspectiva que surge como una evolución de la ciencia de la geografía y fue liderada por el connotado científico Yi-Fu Tuan (1977) y el destacado geógrafo Edward Relph (1976). Los autores antes mencionados elaboraron una perspectiva que describe cómo las personas perciben, identifican y significan el espacio y cómo, dependiendo de las actividades y significados que allí se les atribuye, este se constituye en un "lugar". Esto es, un territorio dotado de identidad que contribuye a su vez a la construcción de la identidad del lugar y de las personas.

El lugar estaría, entonces, definido por la perspectiva empírica que las personas tienen de un espacio. Es decir, las experiencias de quienes ocupan y disfrutan un área son las que hacen que ese lugar sea significativo para ellos y, en su interpretación, para los demás. Esta construcción personal se hace colectiva en la medida que existe una recurrencia temporal e histórica de ese uso. De este modo, se pueden entender los lugares como "localizaciones en las que las personas tienen larga memoria, enriqueciendo, con las indelebles impresiones de su propia niñez, al sentido común de las generaciones futuras. Se puede sostener que los ingenieros pueden crear localizaciones, pero que el tiempo es necesario para crear lugares." (Tuan, 1996: 455). Esto indica, que la trascendencia de una localidad no necesariamente está asentada en el espacio físico por sí mismo, sino en cómo el espacio es o fue usado (Manzo, 2005). Por ende, el valor histórico de una localidad está en la propia memoria de quienes lo habitan y de cómo se representan esas relaciones.

Estos lazos o vínculos, al estar cargados de emociones y sentimientos positivos, van desarrollando una suerte de apego, de afecto dirigido a estos lugares. Para describir y aglutinar estas expresiones de amor, Tuan (1974) acuña el concepto de "Topofilia", entendido como "el lazo afectivo entre las personas y el lugar o el ambiente circundante. Difuso como concepto, vívido y concreto en cuanto experiencia personal" (Tuan, 1974:13). Este concepto es, sin duda, uno de los precursores e inspiradores de la noción del sense of place. Para Tuan, este concepto engloba las diferentes emociones que se despliegan hacia el lugar, pasando de un posible lazo identitario hasta un momento efímero pero intenso.

La importancia del sentido social o colectivo de los lugares radica, entre otros, en que estos procesos, aunque tienen su punto de partida en la experiencia personal, se proyectan al espacio social, nacional e incluso planetario. Esto último sucede en la medida que la recurrencia de la experiencia individual se multiplica y se transmite a través del lenguaje y los símbolos, alojándose en la memoria de las personas y los colectivos. En otras palabras,

"mientras un individuo puede desarrollar un personal sense of place, alrededor de un sitio específico, el lugar social se conoce y comprende a través de un conjunto de personas que lo están creando y reproduciendo a través de la interacción interpersonal, formalizada en conductas sociales, y últimamente persistente en la memoria colectiva" (Stokowsky, 2002:372).

En esos términos, se puede afirmar que si el lugar es socialmente construido, entonces, la creación de un sense of place puede ser vista como una tarea social y no meramente individual.

Los afectos que las personas sienten hacia determinados lugares y las experiencias en las que están basados, son con frecuencia difíciles de definir, categorizar y explicar con precisión en términos lógicos, pero sin duda son de gran importancia para las personas, y pueden afectar a la gestión de los recursos y el desarrollo de políticas (Williams \& Stewart, 1998; Roberts, 1999; Schroeder, 2002; Manzo, 2005). Las experiencias de ocio que las personas tienen en los ambientes naturales pueden ser una parte importante de sus vidas. Cuando la gente tiene experiencias estéticas emocionales que valora especialmente en lugares específicos o tipos de ambientes, estos lugares o ambientes toman particular importancia para ellos y se transforman en lugares especiales. La gente adscribe apego y afecto hacia esos lugares, de una manera parecida como podría hacerlo con un buen 
amigo o un miembro de la familia (Brooks et la., 2006). Cuando una persona pierde un lugar especial o este es alterado a través de la acción humana como una tala o una cosecha o la construcción de un proyecto o un evento natural imprevisto como un incendio o una avalancha, la persona puede experimentar sentimientos como pena o rabia (Williams \& Stewart, 1998; Schroeder, 2002). La riqueza de los significados y sentidos que estos lugares adquieren no son fácilmente comprensibles desde las ópticas cuantitativas, ya que estos, tienen algunas dificultades para la exploración y comprensión de las sutilezas y diversidades de la subjetividad.

La revisión de la literatura antes sintetizada permitió delinear algunas preguntas para la comprensión de la experiencia de ocio y sus alcances para la gestión de un área natural protegida. ¿Existen lugares especiales preferidos por los y las aficionadas para la experiencia de ocio en la naturaleza en los territorios naturales? ¿Cómo se pueden entender y caracterizar los vínculos que establecen las personas con el territorio natural a partir de sus experiencias de ocio en la naturaleza? En términos específicos se plantearon los siguientes propósitos: identificar y caracterizar los vínculos que establecen aficionados de ocio en la naturaleza con algunos territorios protegidos e identificar lugares de especial consideración en un área natural protegida determinada, para los aficionados de ocio en la naturaleza.

\section{Metodología}

Para comprender cómo se vivencia el ocio en la naturaleza, su relación con ella y cómo se hace importante en la vida de las personas, es necesario entender cuáles son los significados que las personas le atribuyen a su experiencia y al territorio donde se desenvuelve. Por tanto, para explorar ese sentido de la vivencia de ocio en la naturaleza, parece más apropiado hacerlo desde una mirada interpretativa que desde una perspectiva que intenta medir, más que comprender. En el caso del ocio en la naturaleza "parece más apropiado entender la experiencia como un todo integrado, más que por la suma de sus partes" (Patterson et al., 1998). De este modo, en esta investigación se abordó la experiencia de las personas como un todo, relatada y na- rrada desde sus sentidos y significados. Esta perspectiva favoreció el desenvolvimiento de las versiones de las propias personas, "permitiendo el despliegue subjetivo y validando relatos que la racionalidad académica en muchas ocasiones desestima; como mitos, creencias, saberes culturales, etc., que por lo demás abundan en relación a la naturaleza" (Bravo, 2010). Para la identificación de variables y el diseño de los instrumentos de esta investigación, se ha optado por el instrumento desarrollado por Schroeder (1996, 1999, 2002), con el fin de identificar los denominados Special Places o Lugares Especiales y el trabajo desarrollado por Daniel Williams en el marco del concepto Place Attachment. Adicionalmente, se consideraron algunas variables de orden general y sociodemográfico que contribuyeron al análisis, estas fueron: la frecuencia de visitación al área, primera visita al área, el género, edad, fecha aproximada de inicio su afición, tipo de aficiones, si desarrolla la actividad al aire libre en compañía o solitario y el lugar de nacimiento, de residencia, de su infancia y juventud.

La herramienta que se escogió para recolectar y levantar los datos es la entrevista de carácter cualitativo y en ella se han incorporado las variables que han permitido identificar lugares de especial significación (special places), vínculos de carácter emocional y funcional (place attachment).

\section{Área de estudio}

Parque Natural de Urkiola, el que se encuentra constituido por la sierra de Aramotz, los Montes del Duranguesado y la sierra de Arangio, los cuales forman parte de la divisoria de aguas cantábrico-mediterránea (Figura $\mathrm{N}^{\circ} 1$ ). Su superficie es de 5.768 hectáreas, Los registros de visitantes al centro de interpretación del Parque arrojan una cifra de 12.067 personas para el 2009 y una media de 16.000 en la última decada (Toki Alai, 2011). Esta cifra, puede resultar engañosa si se le considera como el número total de visitantes al parque, ya que la mayoria de los visitantes y especialmente los aficionados, no se registran, ni se anuncia en el centro de visitantes. El paisaje de Urkiola posee un elevado grado de humanización debido al uso y ocupación que de este territorio se ha realizado desde tiempos inmemoriales. A pesar de ello, cons- 
tituye un paisaje de gran riqueza que puede considerarse de indudable calidad en el marco del País Vasco y representativo de las montañas del ámbito atlántico. Dentro de los límites del Parque Natural de Urkiola, se encuentra la cueva Mariurrika kobea o Mariren kobia, sindicada en la tradición mitológica vasca como la más importante de las moradas de la Diosa Mari o Ama Lurra, quien es el principal personaje sobre el cual se estructura la mitología vasca (Ortiz-Oses \& Mayr, 1982). La vegetación del Parque está formada por diversas comunidades vegetales, entre las que destacan por su importancia los bosques (3.200 ha). Además del bosque, el pastizal de montaña es uno de los elementos más característicos del paisaje de Urkiola, pero no el único, ya que en las escarpadas cumbres rocosas y en las zonas húmedas de los arroyos y esfagnales prosperan gran cantidad de plantas singulares (Toki Alai, 2011).

La muestra se diseñó con carácter intencionado. En particular y, siguiendo las reco-

Figura $\mathrm{N}^{\circ} 1$

Parque Natural de Urkiola

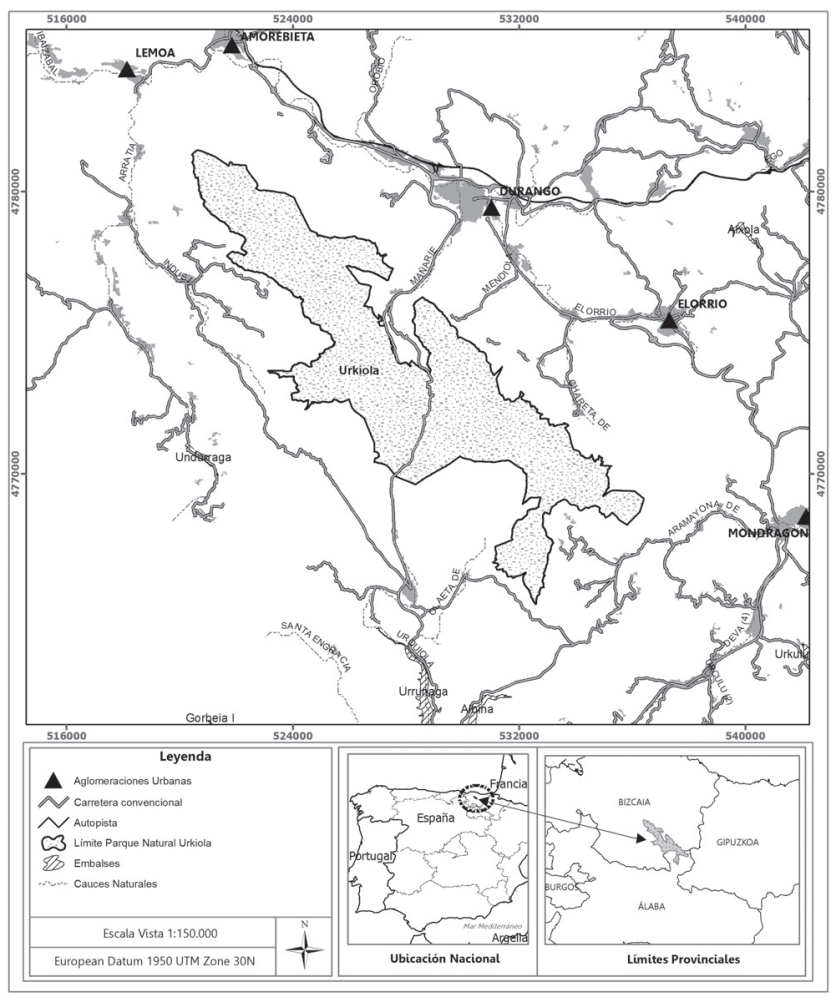

Fuente: Elaboración propia.

mendaciones de Olabuénaga (2003), se optó por el muestreo opinático, donde los entrevistados se escogieron por su conocimiento de la situación o del problema a investigar, en este caso, sujetos que eran conocedores del parque y practicantes regulares de actividades recreativas al aire libre. Se escogió tomar la muestra a través del método "bola de nieve". La muestra final quedó conformada por 20 individuos. 15 hombres y 5 mujeres. El rango de edad varía entre los 32 y 65 años. Para identificar a los entrevistados y entrevistadas, se han utilizado nombres ficticios. El perfil sociodemográfico y de afición de la muestra se precisa en el siguiente Cuadro $N^{\circ} 1$. 
Cuadro $\mathrm{N}^{\circ} 1$

Caracterización de la muestra

\begin{tabular}{|l|r|l|l|l|}
\hline \multicolumn{1}{|c|}{ Informante } & Edad & Genero & $\begin{array}{l}\text { Lugar de } \\
\text { Residencia }\end{array}$ & \multicolumn{1}{|c|}{ Descripción de su afición } \\
\hline E.1. Leo & 34 & Masculino & Durango & Andar, escalar y hacer asados con los amigos. \\
E.2. Emilio & 32 & Masculino & Durango & Espeleología (exploración y estudio de las cuevas). \\
E.3. Josu & 65 & Masculino & Urkiola & Escalar, bicicleta de montaña y andar. \\
E.4. Noel & 48 & Masculino & Durango & $\begin{array}{l}\text { Actividades espirituales, contacto con la na- } \\
\text { turaleza, observación de vida silvestre, esquí } \\
\text { de fondo, de travesía y escalar. }\end{array}$ \\
& & & & \\
E.5. Jaime & 34 & Masculino & Durango & Escalar y andar. \\
E.6. Julio & 56 & Masculino & Durango & Escalar y andar. \\
E.7. Iván & 41 & Masculino & Pamplona & Escalar, ir al monte, bicicleta de montaña y \\
& & & & andar por el bosque. \\
E.8. Manuel & 33 & Masculino & Bilbao & Andar, ir al monte, a escalar alguna vez. \\
E.9. Gabriel & 34 & Masculino & Bilbao & Ir al monte y andar. \\
E.10. Patricio & 32 & Masculino & Bilbao & Ir al monte \\
E.11. Emilio & 51 & Masculino & Durango & Andar, buscar setas, fotografiar e ir con las hijas. \\
E.12. Amelia & 33 & Femenino & Durango & Andar, observar la vida silvestre. \\
E.13. Begoña & 32 & Femenino & Bilbao & Pasear con amigos, ir comer, jugar en el monte. \\
E.14. Rosa & 33 & Femenino & Bilbao & Ir al monte, andar. \\
E.15. Ismael & 42 & Masculino & Burgos & Observar y estudiar fauna silvestre. \\
E.16. Úrsula & 33 & Femenino & Durango & Andar, hacer barbacoas. \\
E.17. Alberto & 38 & Masculino & Mañaria & Cazar aves migratorias. \\
E.18. Carlos & 46 & Masculino & Durango & Andar, hacer monte. \\
E.19. Isabel & 36 & Femenino & Durango & Andar, pasear, ir a comer. \\
E.20. Pablo & 33 & Masculino & Bilbao & Andar, sacar fotos, ir a comer \\
\hline
\end{tabular}

Fuente: Elaboración propia.

\section{Vínculos con el territorio: lugares especiales o Special Places}

De los principales hallazgos que se obtiene de esta investigación, se puede destacar el hecho de que el ocio en la naturaleza provee de múltiples e importantes beneficios a las personas y a la sociedad. En términos específicos, se puede establecer que los beneficios que provee la experiencia de ocio en la naturaleza pueden ser categorizados también como significados, entre los cuales destacan los sentidos atribuidos al lugar. Además se afirma que estos a su vez se revelan en relación con otros significados, es decir, están interrelacionados y dependen los unos de los otros para su concreción. No obstante, esta característica holística de la percepción de los sentidos del lugar y el análisis de los lugares especiales, en particular, permite revelar cualidades específicas de sitios determinados y en un segundo momento del análisis proyectarlos al parque en su totalidad. En cuanto a los lugares que se mostraron como especiales al igual que sus significados, se han seleccionado a partir de dos filtros, en primer lugar, se atendió a la cualidad emergente de estos en el discurso, es decir, la frecuencia de las menciones del lugar $y$, en segundo término, a la densidad, entendida como la relación que este lugar tenía y se manifestaba con otros códigos del 
corpus del discurso. Los lugares especiales que serán destacados y sobre los cuales se hará un desarrollo de su significación son los siguientes: Monte Anboto; Campas del Polpol; Atxarte y El Santuario.

Como se observa, la Figura $N^{\circ} 2$, "Lugares Especiales del Parque Natural de Urkiola", se establece la localización de los principales lugares especiales, destacados la leyenda de estrellas. Aunque en el corpus de la investigación se mencionan bastantes más sitios, los seleccionados son un reflejo fidedigno de los lugares que representan de mejor modo el discurso global de los y las entrevistadas. En el conjunto del discurso, aparecen cerca de 30 lugares especiales, sin embargo, los cuatro seleccionados son los más significativos y representativos en las narraciones de los y las informantes. Un aspecto que llama la atención, es la concentración geográfica de lugares especiales, dentro de una zona más o menos delimitada del Parque. Esto es aun más notorio, si se analiza desde la ausencia de lugares con significación relevante en las zonas localizadas al noroeste y sur del área protegida. Se podría especular que estas zonas no especiales coinciden con superficies que tienen menor desarrollo turístico y menor facilidad de acceso. Pero, también se presenta la cuestión de que el monte Anboto, en tanto morada de Mari y cumbre emblemática, parece ser una suerte de imán de interés y significación, por lo cual, las zonas o áreas que no se encuentran conectadas en tanto rutas en torno a Anboto, pierden atractivo.

En segundo término, el análisis se refiere al relato de los principales significados que le fueron atribuidos a los lugares especiales. Cabe destacar que, siguiendo la estrategia planteada por Schroeder (1996, 1999, 2000, 2002), la atribución de sentidos simbólicos a estos lugares es fruto, principalmente, de la

Figura $\mathrm{N}^{\circ} 2$

Lugares especiales del Parque Natural de Urkiola

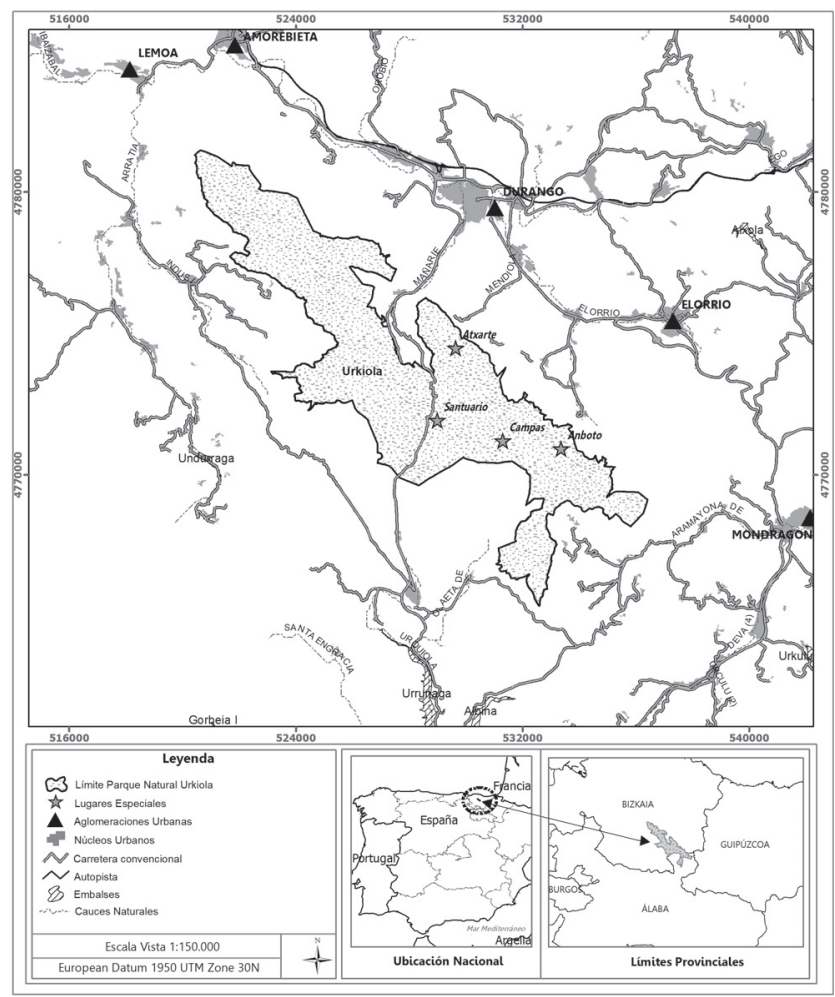

Fuente: Elaboración propia. 
solicitud de descripción de los lugares, para ello se le planteaba a los y las entrevistadas que esta representación podía ser realizada a través de las vistas, olores, sonidos, animales, plantas, ruinas, construcciones, etc. y a partir de la interrogante anterior se les preguntaba ¿qué pensamientos, sensaciones, emociones, recuerdos y/o asociaciones se te vienen a la cabeza cuando piensas en esos lugares?

\section{Lugares especiales del Parque Natural de Urkiola}

Lugar especial, Anboto: la diosa Mari, su morada, el misterio y desafío de la montaña, como señal de identidad. Junto con ser el lugar más mencionado, Anboto no solo es referido a su cumbre, sino que se le asocia a un conjunto de lugares que en sí mismo tienen una importante significación. Destacadísimo lugar toma, de este modo, y surge con fuerza propia la Cueva de la Dama, Cueva de Anboto, Anbotokodama o la Morada de la Dama, debido a la cercanía de la cumbre del Anboto con la denominada Cueva de Mari y, en consideración a la unicidad paisajística del lugar, se ha decidido tratarlo como un solo lugar. Aunque, en el corpus de la investigación se pueden encontrar referencias particulares, estas se encuentran emparentadas en función de los significados y propiedades de ambos lugares. Si bien Anboto cuenta con fama de montaña señera en el ámbito deportivo en el País Vasco, para las entrevistas este se relaciona directamente con un lugar de magia, un sitio donde el misterio y la belleza se reúnen. La espectacularidad de las vistas, el esfuerzo necesario para llegar a la cima o a la cueva, la sensación de riesgo controlado y la presencia de una mitología que alude a la identidad del pueblo vasco, hace de Anboto un lugar de especial importancia y significación para los aficionados.

Como se ha dicho, Anboto es referido como un lugar especial en primer lugar por su condición de morada de Marí, ser mitológico que es ampliamente reconocido y respetado por la mayoría de los y las entrevistadas, "La gente llega a esa mansión, que

\footnotetext{
6 Mari es sindicada como la divinidad máxima de la mitología vasca (Ortiz-Oses \& Mayr, 1982).
}

es un lugar muy mitológico, es la mansión de la dama de Anboto, de Mari, quien es la reina de la mitología vasca" (Josu).

Esta cualidad de Anboto, es particularmente destacable en las personas que referían a la cultura vasca como un elemento importante del Parque Urkiola, para estas personas Anboto tiene un especial simbolismo, "Son montes tuyos y recogen la tradición más antigua, casi a la leyenda, vinculada al primer vasco que vivía más aislado en su caserío, recuperas un poquito esa idea" (Manuel).

Otra característica que se atribuye a Anboto, es su cualidad de desafiar a los y las aficionadas, en las dificultades que ofrece, sumado a las incertidumbres propias de la naturaleza (condiciones climáticas, alturas, terrenos resbaladizos), se encuentra el desafío de alcanzar su cumbre, allí se experimentan sensaciones de manejo del riesgo, de logro y satisfacción. La percepción de competencia y superación es un elemento destacado de las experiencias vividas en Anboto, "El Anboto, es más abrupto, más complicado, más peligroso. El Anboto con todo, está en el límite al que llegan muchos montañeros... está en la frontera entre el monte fácil y el escalar o lo díficil, aunque aun es fáci, en el Anboto, si te caes te puedes matar" (Julio).

Lugar especial, Campas del Polpol: socialización, recreación y escape. Este lugar, situado a los pies de la principal ruta de ascensión al Anboto, es identificado casi unánimemente como un lugar de tranquilidad, reposo y relajo. En los diversos relatos aparece como un lugar de tránsito para alcanzar otras rutas, un alto en el camino, un lugar ideal para descansar y compartir con los y las compañeras de excursión. En todo caso, también se le reconoce su atractivo con características propias, de modo que no son pocas las veces que es un lugar de destino y de recreación. Los principales significados de este lugar se vinculan con la tranquilidad y el descanso, conteniendo una importante significación de escape a la vida cotidiana, sus factores estresantes y sus formalismos. Otro significado atribuido, que aparece como de alto interés para esta investigación fue la asignación de cualidades de sensación de libertad y de amplitud de Polpol, las amplias vistas al macizo de Anboto, Larrano, Alluitz y otros, sugiere 
una oportunidad de espacio para conocer y explorar libremente.

Un aspecto que se revela con particular fuerza, es su asociación con la amistad, con momentos de juego y encuentro, de conversación reposada y sincera. Polpol, emerge así como un lugar especial, donde al amparo de la tranquilidad y el descanso, las relaciones interpersonales se fortalecen, ya que se nutren de la sinceridad y simplicidad de la vida en la naturaleza, "No es que salga una conversación de que bien estamos todos, pero tú simplemente ves las caras y que bien, que bien estamos, un espacio te hace estar en un punto más guay" (Patricio).

Polpol como sitio de descanso incorpora sentidos importantes atribuidos al descanso físico, a la pausa necesaria para continuar la ruta, o para el regreso. Pero también es frecuentemente entendido como un lugar para compartir la comida y la conversación “...esas campas me gustan mucho, no sé si es porque siempre nos sentamos a hacer el amaiketako $^{7}$, o no sé, ese sitio me gusta mucho, es un lugar para descansar, conversar, estar" (Begoña).

Un elemento, que colabora con esta sensación de descanso y reposo es la presencia del agua. Tradicionalmente, el agua supone la posibilidad de recuperación y se puede asociar a descanso. En el caso de Polpol, tiene una condición especial, que se relaciona con las historias personales asociadas a una fuente que brota en la zona y su característico sabor a hierro de sus aguas, ese antecedente es registrado en la memoria de varios de los y las entrevistadas como un recuerdo significativo y con una carga de curiosidad y afecto, "Y luego, yo tengo un especial vicio con la fuente de hierro que está allá abajo, que me conecta más con la parte de la infancia. Yo, de pequeño en el pueblo que yo iba con mi Aitite, mi abuelo, había una fuente con esa agua"(Gabriel).

En el caso de Polpol se aglutinan algunas narraciones que dan cuenta de una cuali-

\footnotetext{
7 Pequeña comida o colación que se hace habitualmente en el país vasco, cercana al mediodía.
}

dad propia de las experiencias de ocio en la naturaleza, la percepción de libertad. Aquí, este significado parece estar acentuado por las vistas y paisajes de este lugar en particular. Queda claro, que no todos los paisajes naturales evocan libertad y esplendor, pareciera que la amplitud y las vistas abiertas son necesarias para solventar esta percepción, "A traves de este contacto, y luego psicológicamente me libera del estrés, me libera, me libero ¡vamos!, oyendo la naturaleza, los pájaros, el río, mirando el paisaje, subiendo a una cumbre, sintiéndome allí grande, eso sí que me libera" (Úrsula).

Lugar especial, Atxarte: desafío y logro. Esta zona del Parque es reconocida por los entrevistados y entrevistadas, como una zona clásica de escaladores. Sus escarpadas paredes y la roca caliza descubierta, la convierten en una verdadera escuela de montaña del País Vasco. A propósito de ese carácter, se menciona como un lugar donde el desafío y la superación están presentes en sus paisajes. Casi en igual medida, casi inseparables y especialmente de parte de los entrevistados que se reconocían como aficionados a la escalada, este lugar es dotado de cualidades mágicas, "Cuando vas a escalar, tienes la altura, andas con cuidado, atento, te pone en un estado mental distinto, más alerta, no sé, tiene una parte mística el estado ese" (Jaime). Los relatos revelan una relación de contacto intenso y misterioso con la roca y la naturaleza. Estas vivencias misteriosas se viven a través de desafíos físicos importantes y se reportan múltiples experiencias óptimas. Llama la atención el relato que se hace de ellas, que es de una asombrosa similitud a la descripción desarrollada por el científico norteamericano Mihalyi Csikszentmihalyi (1997) respecto del estado de Flujo, "Estaba escalando una vía y en un momento me topé con alguna dificultad o exigencia, entonces mi cuerpo, yo, me comencé a sentir poderoso, me sentía capaz de subir a cualquier sitio, en ese momento perdí la percepción del tiempo y me sentía tan fuerte, tan poderoso, que alcancé un estado que no te podría explicar, de pérdida de conciencia, de estar totalmente alineado y armonizado" (Iván).

Atxarte, a su vez, carga con una historia considerada un ejemplo de movimiento ciudadano respecto de la protección de la 
naturaleza y el paisaje. Las narraciones, en este sentido, hacen alusión a un movimiento de escaladores de los años 80, donde estos se colgaron de la roca con propósito de detener el funcionamiento de una cantera. El movimiento ciudadano se extendió por más de dos meses en el sector $y$, finalmente, tuvo éxito. La cantera dejó de funcionar y al día de hoy se observan los restos de la maquinaria utilizada en la extracción de la piedra. El recuerdo de ese pasado de compromiso y movilización es rememorado con orgullo y como un ejemplo de compromiso con las causas ambientales, "...Es un sitio de unas canteras que se consiguieron parar, yo no alcancé a estar ahí, fue en los 80 pero vimos a la gente mayor, cómo pararon la cantera, es especial, fue muy importante" (Leo).

Respecto de Atxarte, también se encuentran significaciones relacionadas con la tranquilidad y la paz. En la narración de los entrevistados, el sector tiene una serie de rincones ocultos que son considerados como reductos de tranquilidad y paz. Lugares donde la vivencia de estas cualidades, favorece la percepción de libertad, "Es un sitio especial, se está a gusto ahí, por la sensación de vistas, es un lugar donde todo lo que ves es agradable. No tienes la sensación de peligro, es una sensación bestial" (Iván).

Lugar especial, El Santuario: espiritualidad, trascendencia y magia. Este lugar, al igual que los antes mencionados, no se circunscribe solo a un sitio limitado que se vincula con el nombre que se le ha asignado a modo genérico. Bajo el signo de El Santuario, confluyen a lo menos tres lugares específicos, pero que se presentan íntimamente asociados en los discursos. Así, el Santuario está constituido por el templo católico de los Santos Antonios Abad y de Padua de Urkiola, los bosques que rodean al santuario y el mirador de las tres cruces. En términos generales, la zona del Santuario se asocia a un lugar mágico, atributo que se coliga, al igual que en casos anteriores, a su paisaje, en el cual las hayas y su antigüedad, parecen jugar un rol especial para la atribución de lugar "mágico", "El sitio es muy mágico, porque todo el caminito este está lleno de hayas muy antiguas, pues esas hayas estan podadas de tradición de aquí, les van cortando las ramas para leña y entonces quedan unas ramas superextrañas (...) Enton- ces ese sitio es mágico, está Ileno de hojitas, es mágico, muy cerca de la iglesia" (Amelia).

Asimismo, el significado de lugar mágico se encuentra vinculado con algunas características tradicionales que se le asignan a los paisajes naturales; silencio, tranquilidad y vistas. Emerge de este modo, la idea de magia en contraste con lo habitual, lo conocido de la ciudad o la urbe, la magia de la naturaleza, se entiende como contraste con la ciudad, "...era como un lugar mágico, entre la luna, la tranquilidad, los ruidos de la naturaleza, el silencio, el silencio de quitar los ruidos que tenemos aquí todos los días, los ruidos de la naturaleza de noche y tal, no sé, me pareció como un lugar superespecial" (Begoña).

Otro significado que surge explícitamente y que además cuenta con una alta densidad, es la atribución en tanto sentido espiritual de El Santuario. Aquí confluyen tanto las experiencias formales guiadas o al amparo de la Iglesia Católica, desarrolladas principalmente en el templo, como las experiencias menos guiadas y que se vinculan más estrechamente con la tradición y mitología vasca, de la cual el santuario parece ser heredero directo, "Por otro lado, el santuario está eso, el vínculo que la Iglesia Católica tenía con toda la mitología vasca, siendo el espacio que al principio ocupaba la diosa vasca, El Santuario también va muy vinculado con esa mitología vasca y no está ahí por casualidad sino que recoge toda esa tradición" (Manuel).

Respecto de la consideración de El Santauario como paisaje, se pueden identificar dos tipos de escenarios que proveen de recuerdos e imágenes que se mantienen con especial cariño de parte de los y las entrevistadas. Por un lado, el paisaje de los bosques, que sugiere tranquilidad, armonía y, como se ha dicho antes, cierto halo de misterio y magia. Por otro, los paisajes abiertos, que ofrecen vistas al valle y especialmente al cordón montañoso desde Atxarte a Anboto, emergen como una posibilidad de contactarse con algo más grande, con la majestuosidad de la naturaleza, "Y luego esa sensación, que te dejan en tu sitio, esa humildad, qué pequeñito que soy, una sensación que te puede pasar en el mar, o en todo el espacio natural que es así, a lo bestia" (Patricio). 


\section{Significados del Parque Natural de Urkiola}

En esta sección, se detallan los denominados Sentidos del Lugar o sense of place, es decir, los vínculos y significados atribuidos al lugar de parte de las personas entrevistadas y que se asignan como producto de su relación con el Parque Natural de Urkiola, superando, de este modo, la mirada sobre un punto en específico del territorio. Como resultado de la interpretación de los datos de esta investigación, surgen siete (7) significados que toman cuerpo como vínculos que las personas establecen con el territorio estudiado. Estos se han establecido en función de afinidades hermenéuticas, vale decir, conjunto de interpretaciones que se pueden aglutinar con otras y que son producto de reiteradas lecturas, análisis y codificaciones preliminares. Son los siguientes: (1) Urkiola como historias de vida; (2) Urkiola como paisaje; (3) Urkiola como lugar de magia, mitología y reserva de cultura vasca; (4) Urkiola como desafío y superación; (5) Urkiola como lugar de contacto y aprendizaje del mundo natural; (6) Urkiola como paz, tranquilidad y bienestar espiritual y (7) Urkiola como diversidad de oferta recreativa.

Urkiola como historias de vida; pertenencia, identidad, hogar y amistad. Esta categoría alude a la atribución que se hace del Parque Natural de Urkiola como un lugar donde se han desarrollado numerosas experiencias personales que fruto de su significación y recurrencia, se transforman en señales de identidad. Una de las características principales de este significado se encuentra en la afirmación de que Urkiola es parte de las historias personales de prácticamente todos los entrevistados y entrevistadas, este sentido es fruto de las vivencias que en ese territorio se han experimentado, su recuerdo y reflexión, configurando una percepción respecto del parque que es relatada como el hogar, la casa y/o el jardín. Lo anterior es frecuentemente relatado como sentido de pertenencia, y este último sentido es considerado como uno de los resultados del denominado logar con identidad o place identity que se haya ligado a los significados simbólicos y emocionales que las personas le atribuyen a los lugares y está basado en la noción que estos ambientes, ofrecen variadas funciones en el desarro-
Ilo de la identidad a través de la promoción de un sentido de pertenencia (Proshansky et al., 1983; Patterson et al., 1998; Williams \& Roggenbuck, 1989; Alcamo \& Bennett, 2005; Brooks et al., 2006). Este tipo de relación queda de manifiesto en la cita de Amelia, aficionada a caminar: "...Es parte de ti, yo suelo decir, que es mío donde esté mi pie, es de otros, pero es mío. La casa no es tan propiedad mía, pero yo la habito. La naturaleza es lo mismo, yo la habito, es parte de mí, no es mía para quedármela y poner una valla, entonces también es un sitio mío..." (Amelia).

Así, la atribución de significados de carácter simbólicos e identitarios se relaciona con una manera de contribuir al desarrollo de la identidad individual (Proshansky, et al., 1983). Estos resultados, se aprecian en diversos estudios que reafirman la importancia que juegan los lugares naturales en la socialización y, específicamente, en la construcción de identidad de los aficionados y aficionadas. Así, se reafirma la idea de que Urkiola, a partir de su condición de espacio natural y tradicional (desde el punto de vista cultural), se constituye en un lugar que favorece la construcción de identidades, esto queda explícito en la cita de Julio, montañista de vasta experiencia: “...Te queda todo eso, son cosas que igual te han aportado a lo mejor que eres y tienes ahora mismo. Aunque, hoy no vayas mucho por allí, de alguna manera yo soy como soy, por las experiencias que he podido tener en un sitio como Urkiola" (Julio).

Otro aspecto que Ilama la atención en este significado es cómo emerge la idea de Urkiola como un lugar propicio para la amistad y las relaciones familiares. De hecho, se manifiesta como un lugar donde las relaciones interpersonales son más honestas y transparentes. Esto es coincidente con los resultados de otras investigaciones que sugieren que la amistad y los amigos contribuyen a que los significados atribuidos a los lugares sean representados de una manera más positiva, acentuando las experiencias emocionales y las atribuciones simbólicas (Schroeder, 2002). Para Wynveen et al. (2010), la amistad se refleja a su vez en la alegría de compartir con otros y también con la calidad de la experiencia. En este estudio aquel significado se representa con tal nivel de importancia, que se puede establecer que el Parque Na- 
tural de Urkiola es significado y valorado en reiteradas ocasiones más como un lugar de socialización y desarrollo de identidad que como espacio natural protegido, destinado a la conservación de la biodiversidad.

Urkiola como paisaje: disfrute estético, majestuosidad y originalidad. En este significado, intereactúan tres elementos que hacen de Urkiola un lugar especial. El disfrute estético que suponen las vistas, aromas y sonidos del parque, sumado a la majestuosidad de sus paredes y montes, junto con la asignación de originalidad, hacen de este significado una construcción compleja. Estos atributos -que parecen ser propios de Urkiola-son, sin embargo, recurrentes en otros estudios localizados en ambientes diversos, de hecho, la utilización de palabras como maravilloso, bello, asombroso, majestuoso se encuentran también en investigaciones desarrolladas en Grand Teton, EE.UU. (Smaldone et al., 2005) para la Gran Barrera de Coral, Australia (Wynveen et al., 2010), lagos, ríos y arboretum (Schroeder, 2002) y ríos en desiertos (Arnould \& Price, 1993). Del mismo modo, las sensaciones que contribuye a vivenciar parecen relativamente similares, por ejemplo; sentimientos de paz, tranquilidad y bienestar son encontrados, entre otros, como consecuencia de la interrelación entre la experiencia del paisaje, la actividad y la persona (Arnould \& Price, 1993; Eisenhauer et al., 2000; Schroeder, 2002; Smaldone et al., 2005; Davenport \& Anderson, 2005; Wynveen et al., 2010). El valor de la experiencia estética es propio del paisaje del parque, atravesando incluso las estaciones del año, "...Sin especificar un sitio concreto, el contraste de la piedra caliza con la hierba, cuando estás en primavera y la hierba florece, y un poco antes que llegue el invierno y se seque la hierba, el contraste que hay con el color grisáceo de la roca con el verde de la hierba, es espectacular, a mí eso me gusta mucho..." (Adolfo).

Otro elemento que resulta interesante de destacar es la diversidad de paisajes que son mencionados a la hora de atribuirles valor estético. Solo en Urkiola los relatos se asocian con diversos paisajes como bosques, cimas, ríos, campas, acantilados y montes. De modo que se puede establecer que el disfrute de lo estético es tan diverso como las mismas experiencias que allí se desarrollan.
Urkiola como lugar de magia, mitología y reserva de cultura vasca. Este significado contiene tres elementos claves que permiten que el parque adquiera el carácter de mágico, mitológico y patrimonio cultural. Estos son: la presencia de la diosa Mari, la vigencia de representaciones de la cultura vasca tradicional campesina y el carácter mágico de sus bosques. En el caso de Mari, parece relevante apuntar que esta característica reviste particular importancia para los habitantes de Durango $^{8}$ y sus alrededores, este aspecto suele no ser tan relevante en las personas que no han nacido o no se han criado en ese entorno, “...Está el tema de la dama de Anboto, que de pequeño, ya de mayor no, pero de pequeño, sí que te hace una conexión más, si vas a un sitio a andar y más encima te dicen que está la Dama de Anboto, no sé si eso te hace soltar endorfinas, no sé, o estás siempre con lo ojos abiertos, a ver qué va a pasar ahora..." (Patricio).

Por otra parte, la presencia de cultura vasca vigente, es un elemento destacado sin distinciones. Estos aspectos parecen ser particularmente importantes, en tanto dotan a Urkiola de un carácter de reservorio de la mitología y cultura vasca tradicional campesina, esto último es refrendado por estudios que enfatizan el rol que las áreas protegidas juegan como "lugares que evocan un sentido de valor histórico y patrimonial, y que se remonta a un tiempo atrás, donde aún el lugar no se veía afectado dramáticamente por el desarrollo" (Schroeder, 2002: 12). En algunos casos específicos, donde el lugar tiene una significación especialmente relevante para las culturas, estos son entendidos como lugares sagrados o divinos (Fredrickson, 1996; Roberts, 1999; Alcamo \& Bennett, 2005). En este sentido, debemos afirmar que para este estudio, este significado de sacro o divino no emergió con ese carácter.

Respecto de la cualidad mágica de los bosques, esta se puede explicar por la presencia de seres mitológicos, por su condición de sitio que permite retroceder en el tiempo y por la presencia de bosques de hayas, los que tradicionalmente han sido asociados a

\footnotetext{
8 Poblado ubicado a los pies de la cara noreste del monte Anboto.
} 
la presencia de seres mágicos y encantados, "los bosques parecen estar entre los mejores ambientes para evocar experiencias de misterio, por la forma en que ocultan lo que contienen. Quizás es por esto, que en el folclore europeo los héroes o heroínas, frecuentemente comienza con el héroe entrando al bosque" (Schroeder, 1999:92). Ursula, aficionada a caminar lo describe explícitamente: "Un bosque de hayas, superbonito, que parece encantado que parece que te van a salir las hadas y los gnomos de debajo de las piedras" (Ursula).

Junto con lo anterior, se debe mencionar la recurrente atribución de halos de misterio a la experiencia de ocio en la naturaleza, en función de su incertidumbre y del no conocimiento cercano y acabado de sus aspectos y elementos.

Urkiola como desafío y superación. Uno de los elementos que caracteriza este significado y que explica la denominación del mismo, es la atribución de Urkiola como un lugar propicio para enfrentar y superar desafíos propios del ocio en la naturaleza. En ese sentido, resulta emblemático el caso de la escalada y el montañismo, actividades que en sí mismas se perciben como desafiantes por la propiedad que manifiestan de estar en condiciones que suponen un obligado manejo y gestión del riesgo. Adicionalmente, la escalada en Atxarte, por ejemplo, involucra desafíos de carácter deportivo y técnicos que otros sitios de la región no ofrecen. Estos, sumado a las condiciones climáticas y ambientales propias de un territorio natural, configura a Urkiola como un lugar de desafío y superación. El riesgo ha sido frecuentemente atribuido como un aspecto destacado en otras investigaciones, donde se enfatiza el valor de convivir, manejar y gestionar el riesgo, considerando la sensación de peligro controlado como algo que beneficia la experiencia (Arnould \& Price, 1993; Ward, 2008) y también relacionado con la posibilidad de explorar y descubrir mundos nuevos y desconocidos (Schroeder, 2002). En el caso de los resultados de este estudio, la asignación de significados referidos a este punto no está evidentemente vinculada al manejo de riesgo, ya que las sensaciones de desafío y logro, no siempre están relacionadas con actividades de aventura, sino que con retos de orden físico (subir en bicicleta, alcanzar la cima de un monte, hacer una ruta de largo aliento) y conductal (pasar días fuera de casa en condiciones no confortables). Sin embargo y a pesar de que algunos relatos, no se revelan como grandes aventuras, las declaraciones de satisfacción por el logro y superación parecen ser igual de relevantes para las personas, “...Una vez subí en bicicleta, sí ¡lo conseguí! Que me pusieron tiempo para hacer una apuesta y ¡lo conseguí! No me pusieron día para cumplirlo, y fui un día con los amigos como para probar y lo cumplí, entonces supercontenta..." (Isabel).

Un aspecto, que parece importante de discutir de este significado es el destacado papel que juega el aprendizaje y desarrollo de competencias propias de la experiencia en la naturaleza, tales como técnicas de caminata, ascensión, escalada, orientación y otras. Estas competencias parecen encontrar un buen lugar para su desarrollo en los márgenes de Urkiola. Este elemento, asociado a los significados de exploración y descubrimiento, es destacado en otros estudios similares (Arnould \& Price, 1993; Schroeder, 2002; Wynveen et al., 2010). Es el caso de Jaime (escalador), quien luego de percatarse de un ramo de flores que había al pie de la pared, indicando o sugiriendo la muerte de un escalador en esa zona, decidió seguir, pero con mucho miedo de por medio: "...Me acuerdo que me bajé de ahí, me quedé, me bajé muerto de miedo, y me acuerdo que fue Leo el que subió y empezamos todo el tema, fue curioso. Lo que aprendí aquella vez, es que esto no es un juego, es algo serio. Era decir ¡bah!, cuidado con lo que haces, fue como un aviso de precaución, yo creo que esto me ayuda a decir ¡hostia!, hay cosas en juego, siempre hay que estar atento..." (Jaime).

El Parque Natural de Urkiola, en este sentido, es considerado como un lugar propicio para desarrollar diversas actividades de ocio en la naturaleza, con diferentes niveles de exigencia, donde el desafío planteado y la satisfacción del logro parecen ser elementos destacados.

Urkiola como lugar de contacto y aprendizaje del mundo natural. Este significado, es considerado como otro de los aspectos claves para entender los sentidos del lugar o sense 
of place que se atribuye al Parque Natural de Urkiola, porque su presencia alude a la consideración que Urkiola es, efectivamente, a pesar de las críticas a su gestión y a los altos grados de urbanización, un lugar de carácter natural, donde las personas logran tener experiencias significativas que las llevan a construir lazos o vínculos importantes con el territorio.

Para efectos de esta investigación se han detectado cuatro elementos que configuran este significado y que se discuten con otras investigaciones. El primero de ellos es la conexión que se establece con los seres y elementos de la naturaleza, el hecho de observar árboles, plantas, aves, insectos o mamíferos en su ambiente natural, sentir y someterse a los elementos de la vida al aire libre, como el frío, el sol, el viento, la oscuridad, el silencio, los sonidos de la naturaleza, configuran un sentimiento particular de contacto con la naturaleza, que a su vez contribuye a la conformación de su identidad. Esto es similar a lo relatado en diversos estudios, donde el contacto con la naturaleza es sindicado como uno de los elementos principales que constituyen los significados de los lugares (Arnould \& Price, 1993; Schroeder, 2002; Davenport \& Anderson, 2005; Smaldone et al., 2005; Wynveen et al., 2010). Para Alberto, un experimentado cazador, las aves son objeto de admiración, cuando no son parte de sus objetivos deportivos: "...Te quedas viendo, qué se yo, un aguilucho, mira que si no sé que, según si te pega un viento norte te pasan los buitres por la cabeza y dices ijoder! Mira qué cacharro, nos gusta, apreciamos cuando no es época de caza. Nos gusta y la respetamos..." (Alberto).

A partir de emociones provocadas por vivencias como la recién descrita, se revela el segundo aspecto a destacar, el sentimiento de admiración acerca del mundo natural, maravillarse por lo bello, majestuoso y espectacular de la naturaleza puede implicar y colaborar a la vivencia de sentimientos de respeto, cuidado y compromiso con la naturaleza. En este sentido, la relación del contacto y aprendizaje del mundo natural, también es descrita como fundamento de la experiencia de ocio por Kaplan \& Kaplan (1989:146), quienes señalan "La coexistencia con otras criaturas, otorga una nueva perspectiva del yo". Este sentimiento de admiración, se transforma habitualmente en sensaciones de humildad, de la convicción de ser parte de algo más grande y hermoso, cuestión que contribuye a la construcción de una identidad más global, más amplia, vinculada con el territorio natural y con el planeta (Naess, 1988; Roberts, 1999; Heintzman, 2010.). Esta nueva identidad, que se ve favorecida por la experiencia de ocio en la naturaleza, es el tercer aspecto a destacar de este significado. En diversos estudios, se plantea que las experiencias extendidas en contacto con la naturaleza contribuyen a la formación de un yo ecológico (Naess, 1988; Schultz, 2002), es decir, de un yo que "se funda en la noción de que existe una conexión fundamental de los seres humanos con los demás seres del planeta. Esto implica que la experiencia del yo ecológico se vive como parte de un todo que abarca las interrelaciones biofísicas, psicológicas y espirituales" (Roberts, 1999:60). Este tipo de identidades se apreció en algunos de los y las entrevistadas.

El último aspecto que se aprecia como interesante para comprender la significación que se le otorga a Urkiola es el de aprendizaje y liderazgo al aire libre. Este sentido, se estructura a partir de dos cuestiones: una relacionada con el impulso y deseo de aprender y compartir vivencias importantes y trascendentes con otros $y$, en segundo término, el vehículo escogido para ese compartir, la enseñanza o liderazgo de experiencias similares. Para Julio, es un medio para entregar felicidad y eso es suficiente motivación para su afición de ocio: "...Porque le regalabas momentos de felicidad, sobre todo por eso, he llevado a muchas personas, he sido profesor de guías de montaña..." (Julio).

Estas vivencias suelen ser consideradas como relevantes para la experiencia de ocio en la naturaleza y para algunos investigadores resultan fundamentales (Hawes, 1978; Pierce, 1980; Tinsley \& Kass, 1978; Roggenbuck et al., 1990, citados por Stein et al., 2003). Si bien para este estudio, los resultados no parecen destacar con gran representatividad este aspecto, sí se puede destacar que el aprendizaje y la enseñanza de actividades de ocio en la naturaleza es un tema que presenta una densidad relevante, es decir, muestra relaciones con diversos significados y códigos 
establecidos en el proceso de interpretación de los datos, constituyéndose, de este modo, en un factor casi de orden transversal a la experiencia de ocio en la naturaleza. Lo anterior confirma la idea de interrelación e interdepencia de los elementos que conforman y construyen los significados de la experiencia de ocio en la naturaleza y del lugar.

Urkiola como paz, tranquilidad y bienestar espiritual. Este significado vuelve a Ilamar la atención acerca de la complejidad e interrelación de las diversas representaciones que se le pueden atribuir a la experiencia de ocio en la naturaleza y al sentido que se le adscribe al lugar. Las sensaciones y sentimientos a los que se remite este punto se vinculan con la paz y la tranquilidad que proveen experiencias de bienestar de carácter mental y/o espiritual. Para Herbert Schroeder (2002:12), "la tranquilidad de estos lugares, es sindicada como una experiencia de relajo y sentido de paz con ellos mismos. Algunos entrevistados, usan la quietud de sus lugares especiales como una oportunidad para meditar y reflexionar, y dijeron sentirse renovados despues de sus visitas". Esto es recurrentemente caracterizado en estudios sobre significados de lugares o place meaning, donde se encuentran descritos como un atributo más que se puede asociar con cierta establidad en las experiencias de ocio en la naturaleza y en los vínculos con el territorio que de ella surgen. El relato de Emilio, espeléologo, es explícito en el sentido antes descrito: "...En invierno, son lugares muy tranquilos si andas por ahí, solo oyes tus pisadas, y si ha nevado casi casi ni eso. Esa tranquilidad, que forma parte del silencio y los ruidos de los pájaros, los animales, las hojas, eso me da mucha tranquilidad, me da paz y sosiego..." (Emilio).

Para esta investigación, este significado surge como uno de los más transversales, ya sea por su representatividad, como por su densidad. Una de las cualidades que se le atribuye de este modo a Urkiola, es su propiedad de actuar como escape a la vida cotidiana y a la urbe. Tanto el ocio en la naturaleza, como el turismo, contienen esta característica como algo propio, es necesario salir del entorno cotidiano, se debe ir al lugar de destino. Para Patterson, et al. (1998), el escape también se expresa en la idea de salir de la rutina diaria y la inmersión en la naturaleza, implica el vivir de otro modo, tomando decisiones y adoptando conductas que no son las habituales en la urbe. El ir al parque es una opción consciente y deseada, tal y como lo expresa Rosa, montañista: "La verdad es que eso, sentimientos de paz, de desconexión, de tranquilidad, de no tanto Bilbao, elijo Urkiola" (Rosa).

Otro de los elementos de este significado, que resulta interesante discutir, es la idea de que no existen entornos particulares que provean tranquilidad y paz, ya que los relatos aluden a diferentes ecosistemas, paisajes y territorios indistintamente, como lugares adecuados para vivir la paz y tranquilidad de la naturaleza. Esto se ve refrendado por los resultados de diversos estudios en diferentes ecosistemas y regiones del mundo que adjudican estas cualidades a lugares diferentes (Arnould \& Price, 1993; Corraliza et al., 1999; Smaldone et al., 2005). Por lo tanto, se puede sugerir que las cualidades de paz y tranquilidad, son significados atribuibles a las experiencias de ocio en la naturaleza de un modo estable y eventualmente no generalizables a paisajes particulares.

Urkiola como diversidad de oferta recreativa. Este significado reúne una serie de características que se consideraron se entendían mejor bajo la denominación de diversidad de oferta recreativa. Entre ellos se destacan: diversidad del paisaje, cercanía física y accesibilidad. Uno de los puntos interesantes de este significado, son las aparentes contradicciones que se pueden observar en el discurso del corpus de la investigación. En principio, se destaca la diversidad que ofrece Urkiola como lugar para la práctica de actividades de ocio, tales como ciclismo, escalada, montañismos, senderismo, picnic, rituales, carreras, otros. En comparación con otros espacios naturales, esta práctica parece ser mejorada sustantivamente cuando se realiza en Urkiola, debido a su paisaje, su carga cultural y su tradición mitológica. En ese sentido, Urkiola es preferido a otros lugares de características geográficas similares, pero que carecen de significación personal y colectiva, "...A mí, me parece que es un sitio supercompleto, para cualquier tipo de gente, puedes ir en siIla de ruedas, en coche y tal, puedes darte un paseo pequeñito, estar de barbacoa sin moverte, puedes ir a un monte o a tres, y puedes 
tomarte algo, es que, puedes ir con niños con el abuelo, es precioso..." (Isabel).

Un segundo elemento, que se revela como importante de este significado, es la cercanía física del parque con los aficionados y aficionadas. Este aspecto, que es considerado por muchos de los informantes como una cuestión positiva, se transforma en una dificultad para algunos de los entrevistados y entrevistadas que viven en Bilbao o que no tienen vehículo personal. Lo anterior evidencia la importancia de contar con accesos fluidos, frecuentes y seguros al parque (Wynveen et al., 2010). Algunos de los entrevistados y entrevistadas valoraron positivamente la facilidad y accesibilidad del parque para personas con discapacidad, pero al igual que en el punto anterior, esto no es del todo compartido por todos los sujetos consultados, ya que también se considera que facilitar en demasía el acceso, a través de la urbanización del parque, conspira directamente contra la experiencia de ocio en la naturaleza y sus consecuentes beneficios. Si bien este significado aparece cargado de consideraciones positivas sobre el parque $y$, en ese sentido, podría pensarse que los y las entrevistadas presentan un alto grado de dependencia funcional o place dependence (Williams \& Roggenbuck, 1989) con el territorio del Parque Natural de Urkiola, cuando fueron consultados, siguiendo las preguntas desarrolladas por Williams \& Roggenbuck (1989) acerca de la singularidad o exclusividad que tenía el parque como lugar para su actividad de ocio (en tanto deporte, afición o hobbie), la gran mayoría manifestó que no tendría dificultad en desarrollarla en otro espacio natural, denotando cierta indiferencia con el valor de Urkiola, como espacio recreativo particular. Sin embargo, cuando los informantes fueron consultados por la reacción que tendrían frente a algunas amenazas explícitas a la condición de área natural del parque, manifestaron casi unánimemente su compromiso y decisión de defenderlo. En este sentido, se puede establecer que el vínculo que las personas desarroIlan con el Parque Natural de Urkiola parece ser sólido y robusto, en tanto sus implicancias emocionales y simbólicas (place identity) actúan como gatilladores de procesos de desarrollo y construcción de identidad personal y colectiva. Asimismo, no se evidenciaron vínculos de dependencias o place dependen- ce, ya que la práctica de sus aficiones puede ser desarrollada en otros lugares o ambientes, sin mayores dificultades aparentes.

\section{Conclusiones}

Junto con compartir las conclusiones del estudio, que en coherencia con el objetivo del mismo están orientadas a dar cuenta de la identificación y caracterización de los vínculos que generan aficionados a la naturaleza con un territorio protegido, este apartado discute los resultados de esta investigación con otros estudios desarrollados en diferentes contextos sociales y ambientales, presentando algunos datos y citas que confirman los hallazgos exhibidos en este artículo y que por lo tanto permiten extraer algunas conclusiones que puedan proyectarse a otras áreas de conservación.

Queda en evidencia en este estudio que las formas de relacionarse e identificarse a partir de las experiencias de ocio con los lugares presenta gran diversidad en forma e intensidad. En el caso de esta investigación, es manifiesto que la mayoría de los aficionados y aficionadas de ocio en la naturaleza generan vínculos de carácter identitario, simbólico y emocional con los territorios naturales, lazos que han sido categorizados frecuentemente con el nombre de place identity (Williams, et al., 1989). Se afirma que las experiencias de ocio orientadas al contacto con la naturaleza, proveen de vivencias que generan la transformación de ese espacio vacío, sin identidad, en un lugar, esto es, un territorio con características e identidad definidas. A su vez, se puede afirmar que el tipo de vínculo que se genera en este proceso, depende del tipo de actividad que se desarrolle, de las características del ambiente (físicas y culturales) y de la experiencia y carácter de la persona o las personas que se involucran en ella (Tuan, 1977). Lo anterior sugiere que las personas o colectivos asignan diferentes valores y significados a los lugares, encontrándose una importante diversidad de atribuciones en función de las prácticas desarrolladas en esos territorios. Sin perjuicio de lo anterior, sí se pueden observar sentidos y atribuciones coincidentes con estudios similares en diferentes contextos, en particular con lo publicado por Schroeder (2002) quien luego de más de 
quince años aplicando la perspectiva de los lugares especiales, ha identificado una serie de significados que se les atribuye a los territorios naturales producto de la experiencia de ocio, por lo cual aventuramos que se podrían considerar más o menos universales y han sido identificadas como significados en nuestro estudio: el contacto con la naturaleza, el disfrute estético, el desafío, la socialización, la identidad y el bienestar espiritual.

La metodología de identificación y representación de los lugares especiales tiene doble interés en la medida que permite, por un lado, conocer cuáles son los lugares de mayor atractivo para los entrevistados y, por otro, comprender los significados atribuidos al parque en general. En particular, se puede señalar que el Parque Natural de Urkiola es considerado por los aficionados y aficionadas al ocio en la naturaleza, como un área protegida que cuenta con una enorme cantidad de sitios considerados como lugares especiales por parte de los aficionados al ocio en la naturaleza.

Urkiola es considerado como un espacio privilegiado para la socialización y el ocio, un territorio donde se puede contactar y disfrutar de la naturaleza. Sin embargo, no deben minimizarse las amenazas que significan para las vivencias de ocio la creciente urbanización y habilitación del parque, ya que la experiencia de ocio en la naturaleza obedece a la posibilidad de conexión con sus elementos y de ella depende, en gran medida, el grado de identificación y pertenencia al lugar de parte de los aficionados y aficionadas. En este sentido, una de las atribuciones que se hace de Urkiola es similar a la que establecen Gunderson \& Watson (2007), quienes describen entre sus tipos de significados que identifican los individuos que visitan frecuentemente el área protegida Montana's Bitterroot National Forest, se encuentra la naturalidad del lugar, la escasez de caminos (como algo positivo) y la belleza escénica.

Se puede señalar que Urkiola, como lugar natural, ofrece en particular oportunidades relevantes de experimentar paz y bienestar espiritual y vivenciar magia y cultura vasca. Este hallazgo se puede considerar singular en la literatura revisada. A su vez se puede concluir que el Parque Natural de Urkiola cumple con ofrecer las diferentes alterna- tivas y oportunidades para las cuales fue creado, no obstante lo anterior, las acciones destinadas a promover experiencias de ocio significativas y de contacto con la naturaleza no son especialmente apreciadas por los sujetos de la investigación. Por el contrario, es recurrente la percepción de que algunas obras de infraestructura y las restricciones impuestas por la administración del parque van en el sentido contrario. Algunas medidas destinadas a conservar los valores naturales de la zona son percibidas por los aficionados y aficionadas, como disposiciones que más bien restringen $y / 0$ limitan la experiencia de ocio y, así, disminuyen las posibilidades de generación de identidad personal y colectiva ligada al parque. A partir de los resultados de esta investigación, también se puede afirmar que la experiencia de ocio en la naturaleza es una fuente relevante de sentidos del lugar, aunque no la única, ni necesariamente la principal. En el caso de Urkiola al igual que otras áreas de conservación como la Gran Barrera de Coral, en Australia (Wynveen et al., 2010) y los Alpes suizos (Kianicka et al., 2006), los aficionados perciben que ellas proveen, oportunidades de ocio de orden individual y colectivas, que son evaluadas como satisfactorias de sus intereses recreativos.

Las prácticas de ocio en la naturaleza consolidadas y permanentes, que se desarrollan dentro de los límites de un área conservación natural como el Parque Natural de Urkiola, tienden a generar conductas de admiración, cuidado y compromiso ambiental en los aficionados y aficionadas. En sintonía con este hallazgo, un estudio desarrollado con visitantes del Parque Nacional de las Montañas Rocosas, Colorado, en Estados Unidos y firmado por Brooks, et al. (2006), señala que algunos de los aspectos que contribuyen a formar vínculos más estrechos y profundos con los lugares, se relacionan estrechamente con las prácticas de ocio en la naturaleza

Se observa que los sujetos del estudio adscriben a las áreas naturales, significados de privacidad, introspección y autorreflexión, esto coincide con lo señalado por Manzo (2005), De este modo, se puede afirmar que más allá del caso particular de Urkiola, el ocio en la naturaleza es una vía estimulante y libertaria que colabora decididamente en 
el desarrollo personal y sostenibilidad ambiental, en tanto funda, a partir de vivencias significativas, lazos profundos con el mundo natural. En este sentido, coincide con las propuestas de Richard Louv quien no solo identifica la experiencia en áreas naturales protegidas como fundamental en el desarrollo de las personas, sino que su ausencia en la formación de los niños, generan déficit que afectan el desarrollo futuro de las personas y el medio ambiente (Louv, 2005).

No considerar de modo riguroso los intereses y experiencias de las personas o usuarios (visitantes, turistas, vecinos, profesionales y científicos) en la toma de decisiones y en la gestión de estos espacios, ha traído como consecuencia, entre otros efectos negativos, que: el público no se encuentre satisfecho con los servicios y oportunidades de vivencia que ofrecen las administraciones (Corraliza et al., 1999; Manning, 1999); hayan aumentado los tipos y niveles de los impactos ambientales por el uso recreativo (Hampton \& Cole, 2003) y se hayan presentado casos de pérdida de apoyo para las causas conservacionistas (Davenport et al., 2010). De este modo, se debe destacar que la comprensión de la importancia y significación que las personas le atribuyen a estos espacios naturales y los vínculos que con ellas se generan, permitiría a los gestores de estas áreas proveer de mejores y mayores oportunidades de ocio a las personas que acuden a estos espacios con la intención de recrearse y así garantizar la generación de vinculos profundos, afectivos e identitarios entre los visitantes y las áreas protegidas.

\section{Referencias bibliográficas}

ALCAMO, J. \& BENNETT, E. Ecosystems and human well-being: a framework for assessment / Millennium Ecosystem Assesment. Washington: Island Press, 2005.

ANDERSON, D. \& FULTON, D. Experience Preferences as Mediators of the Wildlife Related Recreation Participation: Place Attachment Relationship. Human Dimensions of Wildlife, 2008, Vol. 13, № 2, p. 73-88.

ARNOULD, E. \& PRICE, L. River Magic: Extraordinary Experience and the extenden
Service Encounter. Journal of Consumer Research, 1993, p. 24-45.

BRAVO, C. Hacia un Narrativa de la Naturaleza: La Psicología ante el reto Sustentable. Polis, 2010, Vol. 9, № 26, 2010, p. 223-231.

BROOKS, J.; TITRE, J. \& WALLACE, G. What does it mean to visit Rocky Mountain Park? Visitors tell their stories in Colorado. In: CAMARDA, I.; MANFREDO, M.J.; TEEL, T.L. \& MULAS, F. Global challenges of Parks and Protected Areas Management Proceedings of the Ninth Intenational Symposium on Society and Resource Management. Sassary: Carlo Delfino Editore, 2004, p. 87-109.

BROOKS, J.; WALLACE, G. \& WILLIAMS, D. Place as Relationship Partner: An Alternative Metaphor for Understanding the Quality of Visitor Experience in a Backcountry Setting. Leisure Sciences, 2006, Vol. 28, № 4, p. 331349.

CORDELL, H.K. \& SUPER, R.G. Trends in American's Outdoor Recreation. In: GARTNER, C.W. \& LIME, W.D. (editors). Trends in Outdoor Recreation, Leisure and Tourism. London: CABI Publishing, 2000, p. 75-90.

CORRALIZA, J.; GARCÍA NAVARRO, J. y VALERO, E. Parques Naturales en España: conservación y disfrute. Madrid: Alfonso Martin, 1999.

CSIKSZENTMIHALYI, M. Fluir: Una PSicología de la Felicidad. Barcelona: Kairos, 1997.

CSIKSZENTMIHALYI, M. \& KLEIBER, A. D. Leisure and Sel-Actualization. In: DRIVER, B.; BROWN, J.P. \& PETERSON, L.G. Benefits of Leisure. Chelsea: Venture Publishing, 1991, p. 91-119.

CUENCA, M. Ocio Humanista. Bilbao: Universidad de Deusto, 2003.

CUENCA, M. Aproximación multidisciplinar a los estudios de ocio. Bilbao: Universidad de Deusto, 2006.

CUENCA, M. La apropiación espacial del ocio, una mirada desde el siglo XXI. En: LAZCANO, I. \& DOISTUA, J. Espacio y experien- 
cia de ocio: consolidación, transformación y virtualidad. Bilbao: Universidad de Deusto, 2010, p. 15-54.

DATTILO, J.; HOWARD, D. \& YOUNGKHILL, L. The Complex and Dinamic Nature of Leisure Experience. Journal of Leisure Research, 1994, Vol. 26, №3, p. 195-211.

DAVENPORT, M. \& ANDERSON, D. Getting From of Place to Place-Bases Management: An Interpretative Investigation of Place Meanings an percpetions of Landscape Change. Society and Natural Resources, 2005, Vol. $16, N^{\circ} 8$, p. 625-641.

DAVENPORT, M.; BAKER, M.; LEAHY, J. \& ANDERSON, D. Exploring Multiple Place Meanings at an Illinois State Park. Journal of Park and Recreation Administration, 2010, Vol. 28, $\mathrm{N}^{\circ} 1$, p. 52-69.

DRIVER, B.; BROWN, P. \& PETERSON, G. Benefits of leisure. Pennsylvania: Venture Publishing, 1991.

DRIVER, B.; TINSLEY, H. \& MANFREDO, $M$. The paragraphs about leisure and recreation experience preference scales: Two inventories designed to assess the breadth of the perceived psychological benefits of leisure. In: DRIVER, B.; BROWN, P. \& PETERSON, G. Benefits of Leisure. Palo Alto: State College, Venture, 1991, p. 263-286.

DRIVER, B.; MANFREDO, M. \& TARRANT, M. Meisuring Leisure Motivation: A Meta.Analysis of the Recreation Experience Preference Scale. Journal of Leisure Research, 1996, p. 182-213.

DRIVER, B.; DUSTIN, D.; BALTIC, T.; ELSNER, G. \& PETERSON, G. Nature and The Human Spirit. Palo Alto: Venture Publishing, 1999.

EISENHAUER, B.; KRANNICH， R. \& BLAHNA, D. Attachments to Special Places on Public Lands: An Analysis of Activities, Reason for Attachments, and Community Connections. Society \& Natural Resources, 2000, Vol. 13, $\mathrm{N}^{\circ} 5$, p. 421-441.

FREDRICKSON, L. Exploring Spiritual Benefits of Person Nature Interactions Through an Ecosystem Management Approach. Minnesota: University of Minnesota, 1996.

HAMPTON, B. \& COLE, D. NOLS Soft Paths: how tu enjoy the wilderness without harming it. Pennsylvania: National Outdoor Leaderschip School, 2003.

HEINTZMAN, P. Nature-Based Recreation and Spirituality: A Complex Relationship. Leisure Sciences, 2001, Vol. 28, № 1, p. 73-89.

HENDERSON, K.; BIALESCHKI, D.; HEMINGWAY, J.; HODGES, J.; KIVEL, B. \& SESSOMS SOUGLAS, H. Introduction to Recreation and Leisure Service. Palo Alto: Venture Publishing, 2001.

IBRAHIM, H. \& CORDES, K. Outdoor Recreation. Dubuque: WCB Brown \& Benchmark, 1993.

ISO-AHOLA, S. The social psychology of leisure and recreation. Dubuque: Brown \& Benchmark, 1980.

KAPLAN, S. \& KAPLAN, R. The Experience of Nature. New York: Cambridge University, 1989.

KIANICKA, S.; BUCHECKER, M.; HUNZIKER, M. \& MÜLLER-BÖKER, U. Locals' and Tourists' Sense of Place: a case Study of a Swiss Alpine Village. Mountain Research and Devolopment, 2006, Vol. 26, № 1, p. 55-63.

LOUV, R. The Last Child in the Woods. Londres: Atlantic Books, 2005.

MANELL, R. \& KLEIBER, D. A Social Psichology of Leisure. Ontario: Venture Publishing, 1997.

MANNING, R. Studies in Outdoor Recreation. Oregon: Oregon State University, 1999.

MANZO, L. For better or worse: Exploring multiple dimensions of place meaning. Journal of Environmental Psychology, 2005, Vol. $25, \mathrm{~N}^{\circ} 1$, p. 67-86.

MAX-NEEF, M.; ELIZALDE, A. y HOPENHAYN, M. Desarrollo a Escala Humana. Una opción para el futuro. Santiago de Chile: CEPAUR, 1986. 
NAESS, A. Thinking Like a Mountain. Philadelphia: New Society, 1998.

NEULINGER, J. The Psycholgy of Leisure. Springfield: Charles C. Thomas, 1974.

OLABUÉnAGA, J.I. Metodología de la Investigación Cualitativa. Bilbao: Universidad de Deusto, 2003.

ORTIZ-OSES, A. \& MAYR, F. El inconsciente colectivo Vasco. San Sebastián: Txertoa, 1982.

PATTERSON, M.; WATSON, A.; WILLIAMS, D. \& ROGGENBUCK, J. An Hermeneutic approach to Studying the Nature of Wilderness Experience. Journal of Leisure Research, 1998, Vol. 30, № 4, p. 423-452.

PIGRAM, J. \& JENKINS, J. Outdoor Recreation Managment. New York: Routledge, 1999.

PROSHANSKY, H.; FABIAN, A. \& KAMINOF, R. Place Identity: Physical world and socialization of the self. Journal of Environmental Psychology, 1983, Vol. 3, p. 57-83.

QUINLAN-CUTLER, S. \& CARMICHAEL, B.A. The Dimension of the Tourist Experience. In: MORGAN, M.; LUGOSI, P. \& RITCHIE, B. (editors). The Tourism an Leisure Experience. Bristol: Channel View Publications, 2010, p. 3-26.

RELPH, E. Place and Placelesness. Londres: Pion, 1976.

RIED, A. El ocio al aire libre en contacto con la naturaleza. Bilbao: Tesis doctoral, Universidad de Deusto, 2012.

ROBERTS, E. Place and Spirit in Public Land Management. In: DRIVER, B.; DUSTIN, D.; BALTIC T.; ELSNER, G. \& PETERSON, G. (editors). Nature and the Human Spirit. Toward an Expanded Land Management Ethic. Pennsylvania: Venture Publishing, 1999, p. 61-79.

ROGGENBUCK, J. \& DRIVER, B. Benefits of Nonfacilitated Uses of Wilderness. Centennial: USDA Forest Service, 2000.
SCHROEDER, H. Ecology of the heart: understand how people experience natural enviroments. In: EWERT, A.W. Natural Resource Management: The Human Dimension. Boulder: Westview Press, 1996, p. 13-27.

SCHROEDER, H. Psyche, Nature, and Mistery: some psychological perspectives on the values of natural environments. In: DRIVER, B.; DUSTIN, D.; BALTIC, T.; ELSNER, G. \& PETERSON, G. (editors). Nature and the Human Spirit. Palo Alto: Venture Publishing, 1999, p. 80-95.

SCHROEDER, H. What makes a place special. In: BENGSTON, D. (editors). Applications of conputer-aided in text analysis in natural resource. Saint Paul: Departament of Agriculture, Forest Service US., 2000, p. 7-11.

SCHROEDER, H. Experience nature in Special Places. Journal of Forestry, 2002, Vol. 100, No 5, p. 8-14.

SCHULTZ, P.W. Inclusión with nature: The Psychology of Human-Nature Relations. Boston: Kluwer, 2002.

SMALDONE, D.; HARRIS, C.; SANYAL, N. \& LIND, D. Place Attachment and Management of Critical Park Issues in Grand Teton National Park. Journal of Park and Recreation Administration, 2005, Vol. 23, № 1, p. 90-114.

STEIN, T.; DENNY, C. \& PENNISI, L. Using Visitors' Motivations to Provide Learning Opportunities at Water-based Recreation Areas. Journal of Sustainable Tourism, 2003, Vol. 11, $\mathrm{N}^{\circ}$ 5, p. 404-422.

STOKOWSKY, P. Languaje of Places and Discoursses of Power: Constructing New Sense of Place. Journal of Leisure Research, 2002, Vol. 34, No 4, p. 368-382.

TARRANT, A.M.; BRIGHT, D.A.; SMITH, E. \& CORDELL, H.K. Motivations, Attitudes, Preferences, and Satisfactions among outdoor recreationist. In: CORDELL, H.K. (editor). Outdoor Recreation in American Life. Champaign: Sagamore Publishing, 1999, p.404431.

TINSLEY, H. \& TINSLEY, D. A theory of attributes, benefits and causes of leisure ex- 
perience. Leisure Science, 1986, Vol. 8, N 1, p. 1-45.

TUAN, Y.-F. Topofilia. Madrid: Melusina, 1974.

TUAN, Y.-F. Space and Place. London: Arnold, 1977.

TUAN, Y.-F. Space and Place: Humanistic Perspective. In: AGNEW, J.; LIVINGSTONE, D. \& ROGERS, A. (editors). Human Geography. An Esential Antology. Oxford: Blackwell, 1996, p. 233-246.

UNIÓN INTERNACIONAL PARA LA CONSERVACIÓN DE LA NATURALEZA (UICN). Recomendaciones $V$ Congreso Mundial de Parques. Congreso Mundial de Parques. Durban: UICN, 2003.

WARD, W.C. Perceptions of Risks and Benefits of an Outdoor Adventure. Indiana: Indian University, 2008.

WILLIAMS, D.R.; PATTERSON, M.E.; ROGGENBUCK, J.W. \& WATSON, A.E. Beyond the commodity metaphor: Examining emotional and symbolic attachment to place. Leisure Sciences, 1992, Vol. 14, N 1, p. 29-46.
WILLIAMS, D.R. \& ROGGENBUCK, J. Measuring Place Attachment: Some Preliminary Results. Blacksburg: Department of Forestry, 1989.

WILLIAMS, D.R. \& STEWART, S. Sense of Place. An Elusive concept is findinf home in Ecosystem Management. Journal of Forestry, 1998, Vol. 96, № 5, p. 18-23.

WORLD LEISURE AND RECREATION. International Charter for Leisure Education. ELRA European Leisure and Recreation Association, 1994.

WYNVEEN, J.C.; KYLE, T.G. \& SUTTON, G.S. Place Meanings Ascribed to Marine Settings: The Case of the Great Barrier Reef Marine Park. Leisure Science, 2010, Vol. 32, No 3, p. 270-287. 
